Article

\title{
Remote Sensing of Shrubland Drying in the South-East Mediterranean, 1995-2010: Water-Use-Efficiency-Based Mapping of Biomass Change
}

\section{Maxim Shoshany ${ }^{1, *}$ and Lev Karnibad ${ }^{2}$}

1 Mapping and Geoinformation Engineering, Faculty of Civil \& Environmental Engineering, Technion-Israel Institute of Technology, Haifa 32000, Israel

2 Agricultural Engineering, Faculty of Civil \& Environmental Engineering, Technion-Israel Institute of Technology, Haifa 32000, Israel; E-Mail: lev.a.karnibad@gmail.com

* Author to whom correspondence should be addressed; E-Mail: maximsh@tx.technion.ac.il; Tel.: +972-4-829-2361 (ext. 123); Fax: +972-4-829-5708.

Academic Editors: Arnon Karnieli and Prasad S. Thenkabail

Received: 29 July 2014 / Accepted: 2 February 2015 / Published: 26 February 2015

\begin{abstract}
Recent climate studies of the South-Eastern Mediterranean indicate an increase in drought frequencies and decreasing water resources since the turn of the century. A four-phase methodology was developed for assessing above-ground biomass changes in shrublands caused by these recent trends. Firstly, we generalized the function $\mathrm{SB}=0.008 \mathrm{MAP}^{1.54}$ describing the shrublands above-ground biomass ( $\mathrm{SB}$ ) dependence on mean annual precipitation (MAP) for areas of full shrub cover. Secondly, relationships between MAP and NDVI were formalized, allowing an estimation of precipitation levels from observed NDVI values (MAPNDVI). Thirdly, relative water-use efficiency (RWUE) was defined as the ratio between MAPNDVI and MAP. Finally, the function $\mathrm{SB}_{\mathrm{RWUE}}=0.008 \mathrm{MAP}^{0.54+\mathrm{RWUE}}$ was formalized, utilizing RWUE in estimating shrublands biomass. This methodology was implemented using Landsat TM images (1994 to 2011) for an area between the Judean Mountains and the deserts bordering them to the east and south. More than $50 \%$ of the study area revealed low biomass change $\left( \pm 0.2 \mathrm{~kg} / \mathrm{m}^{2}\right)$, compared with $30 \%$ of the woodlands of the Jerusalem Mountains, where biomass increased between 0.2 and $1.4 \mathrm{~kg} / \mathrm{m}^{2}$ and with $50 \%$ of the semi-arid shrublands, where it decreased between 0.2 and $1.4 \mathrm{~kg} / \mathrm{m}^{2}$. These results suggest that aridity lines in southern Israel are migrating northwards.
\end{abstract}


Keywords: desert-fringe ecosystems; climate change; shrubland biomass; remote sensing; water-use efficiency

\section{Introduction}

Semi-arid to arid transition zones in the eastern Mediterranean region are among the hot spots of global climate change and desertification [1,2] . Based on CMIP3 simulation models, Mariotti et al. [3] assessed the changes expected in the Mediterranean region during the current century. In addition to predicting a " $20 \%$ decrease in land surface water availability... due to precipitation reduction and warming-enhanced evaporation..." they claimed that "20th century simulations indicate that the 'transition' toward drier conditions has already started to occur and has accelerated around the turn of the century towards the larger rates projected for the 21st century." Data published by the Hydrological Service of Israel [4] concerning rainfall fluctuations for the entire country between 1994 and 2011 indicates that except for 2002, 2003 and 2011, rainfall every year since 1997 (i.e., for 14 of the 17 years) was lower than the 1931-1990 average, thus suggesting decreasing water availability for the natural vegetation. However, there is no information where such reduced rainfall had taken place, and what impact it had on natural ecosystems. According to existing studies, decreasing water availability is expected to reduce productivity in desert-fringe ecosystems in general and in semi-arid shrublands in particular [5-8]. This article aims at assessing trends of biomass change in the shrublands of the climatic gradient between sub-humid and arid zones in Central Israel as indicators of rainfall variations.

Wide regional mapping of temporal trends of vegetation change using spectral indices has attracted significant attention in remote sensing of drylands (e.g., [9]). In between these studies, only a limited number of works were concerned with developing remote-sensing indicators of above-ground shrublands biomass (e.g., $[10,11])$ especially along semi-arid to arid climatic gradients. Shoshany and Karnibad [12] showed that integrating NDVI with mean annual precipitation (MAP) information might improve shrublands biomass mapping along such gradients. We now suggest further development of this approach through the use of Water-Use Efficiency (WUE) as a parameter relating plant productivity to available water (e.g., [13]). The aim of using a WUE measure is to account for a decrease in ecosystem productivity that is due to decreasing water availability and/or increasing human disturbance relative to its level at the beginning of the monitoring period (mid 1990s in this study). The new methodology will be established on modeling relationships between NDVI and WUE and then among MAP, WUE and shrublands biomass. Landsat TM Images of the end of each summer between 1994 and 2011 will be processed according to these models, yielding biomass estimates for the beginning and end of this time span. This information will serve an analysis of the changes in biomass within the context of decreasing water resources in our region.

\section{Generalizing Biomass versus Mean Annual Precipitation (MAP)}

Shoshany and Karnibad [12] generalized the relationships between mean annual precipitation (MAP) and shrubland biomass using two exponential functions: one for Mediterranean and semi-arid regions and another that better fits desert marginal areas (Figure 1a,b). Deviations from these generalized 
relationships represent the diversity of ecohydrological processes taking place and human disturbance regimes. A better understanding of these sources of influence may be gained by assessing the deviations from a baseline that represents complete shrub-cover biomass as obtained for different MAP levels (e.g., [14]). Data that facilitates the calculation of such a baseline was derived for this purpose from several studies as follows:

- Extrapolation of data for full shrub coverage from Evenari [15] yielded $0.27 \mathrm{~kg} / \mathrm{m}^{2}$ for Artemisia in the Negev Desert, with 8 to $12 \mathrm{~cm} / \mathrm{yr}$ rainfall.

- Sternberg and Shoshany [16] reported $1 \mathrm{~kg} / \mathrm{m}^{2}$ for Sarcoproterium spinosum in the Negev Desert margins, with $25 \mathrm{~cm} / \mathrm{yr}$ rainfall.

- Sternberg and Shoshany [16] reported $2.27 \mathrm{~kg} / \mathrm{m}^{2}$ for Quercus calliprinus in the Judean Highlands, with $45 \mathrm{~cm} / \mathrm{yr}$ rainfall.

- Cerrillo and Oyonarte [17] reported $4.4 \mathrm{~kg} / \mathrm{m}^{2}$ and Alrababah et al. [18] $3.94 \mathrm{~kg} / \mathrm{m}^{2}$ for Quercus calliprinus, with 50 to $55 \mathrm{~cm} / \mathrm{yr}$ rainfall.

- Saglam et al. [19] reported $5.5 \mathrm{~kg} / \mathrm{m}^{2}$ (live biomass) for tall shrubs dominated by the Quercus-Phillyraea alliance and by Q. coccifera in western Turkey (Kesan site), with $65 \mathrm{~cm} / \mathrm{yr}$ rainfall.

The following function was selected from the different statistically significant functions to represent the baseline for shrubland biomass (SB) based on the above data:

$$
\mathrm{SB}(100 \% \text { cover })=0.008 \mathrm{MAP}^{1.54}
$$

The differences between this baseline and the functions generalizing observed biomass levels (Figure 1) indicate the high impact of climate changes, droughts and human disturbances on the productivity of ecosystems along semi-arid climatic gradients.

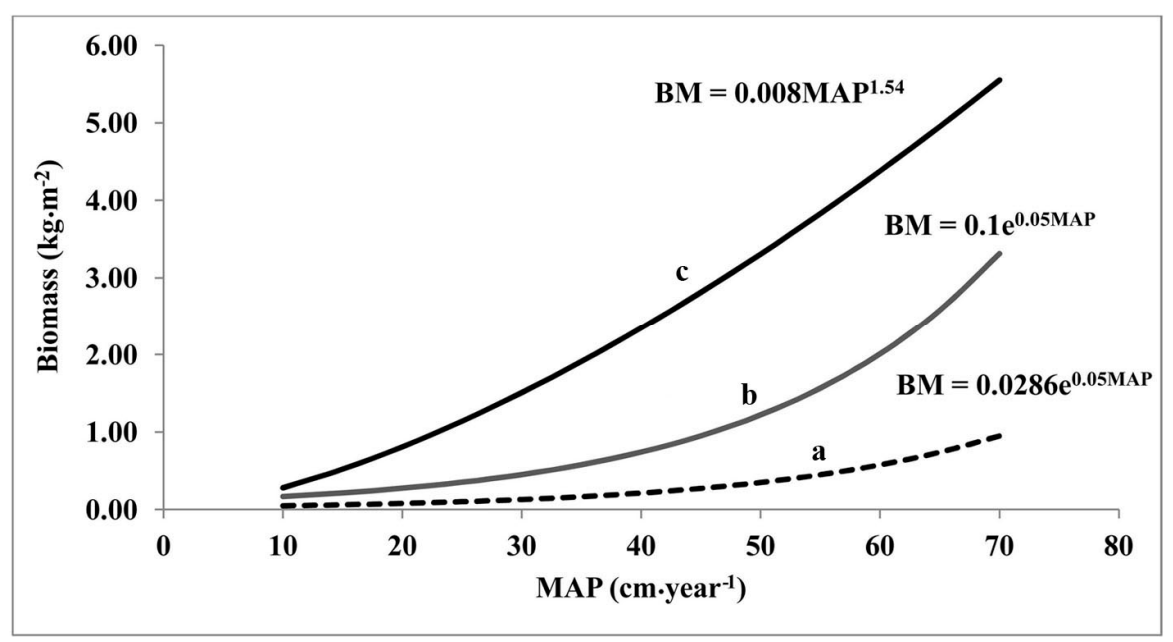

Figure 1. Generalized relationships between shrubland biomass and mean annual precipitation (MAP): (a) for desert fringe areas; (b) for sites representing different disturbance levels across the Mediterranean and semi-arid regions; and (c) for $100 \%$ shrub cover. 


\section{Water-Use Efficiency and NDVI}

Stanhill [20] defined WUE as:

$$
W U E=\frac{\text { Volume of water used productively }}{\text { Volume of water potentially available }}
$$

Remote sensing has been shown to enable WUE mapping over wide regions. Two main parameterizations were developed for this purpose: (i) a measure based on the ratio between gross primary production and evapotranspiration (ET); (ii) rainfall-use efficiency (RUE), calculated as the ratio between annual net primary productivity and rainfall. Referring to the calculation of WUE based on ET estimates and following Kustas and Norman [21], Lu and Zhuang [22] claimed that "ET is a complex process that is related to many variables, which cannot be detected directly by remote sensing techniques" and concluded that "at a regional or continental scale remotely-sensed ET estimation is far from satisfactory" (p. 1925). Difficulties in estimating ET are further complicated in transition zones between sub-humid and arid zones because of the high spatial heterogeneity of soil, rock and vegetation patterns. Thus, uncertainties regarding sources for the differences in ET hamper their utilization in assessing trends in productivity change.

Rain-use efficiency is commonly calculated as an annually integrated measure representing both herbaceous growth and shrubs (e.g., $[23,24]$ ). Since we are interested mainly in the biomass of shrubs and dwarf shrubs, which are the life forms of the highest biomass in vast semi-arid regions and which represent the resilience of such systems, it is best to monitor them when they are separated from herbaceous growth. Across vast semi-arid regions, such separation can be achieved at the end of the dry summer season [25], when herbaceous growth is either completely dry or removed by grazing or fire. The approach developed here deviates from RUE-based approaches in two aspects: first, it examines vegetation conditions only at a specific time during the annual growth cycle; second, it refers to mean annual precipitation rather than to annual rainfall, as shrub growth responds both to annual and long-term water availability owing to shrubs' access to ground water through their root systems.

The conceptual framework presented here (Figure 2) modifies Stanhill [20] definition (Equation (2)). While mean annual precipitation may represent the volume of water potentially available, the productive use of water is interpreted here as the amount of precipitation corresponding to amount of growth. NDVI (= ( RIR $\left._{\text {NIR }} \mathrm{R}_{\mathrm{RED}}\right) /\left(\mathrm{R}_{\mathrm{NIR}}+\mathrm{R}_{\mathrm{RED}}\right)$, where RNIR and RRED are the reflectances obtained for the NIR and RED spectral bands), a widely used spectral vegetation index, may serve as a proxy for vegetation growth. The amount of rainfall corresponding to NDVI levels (e.g., [26-28] ) may then represent the productive use of water in relative terms. Water use efficiency of 1 would be obtained by the maximal level of NDVI for each MAP level, thus, the following function would be generalized for the rainfall gradient:

$$
\operatorname{MAP}_{\mathrm{NDVI}}(\mathrm{Max} \text { NDVI })=f(\mathrm{MAX}(\mathrm{NDVI}) \rightarrow \mathrm{MAP})
$$

These relationships will be derived from NDVI values computed for sites representing undisturbed ecosystems across the climatic gradient (Section 6.2). 
Generalizing a function representing relationships between maximal growth (NDVI) and MAP levels along the rainfall gradient

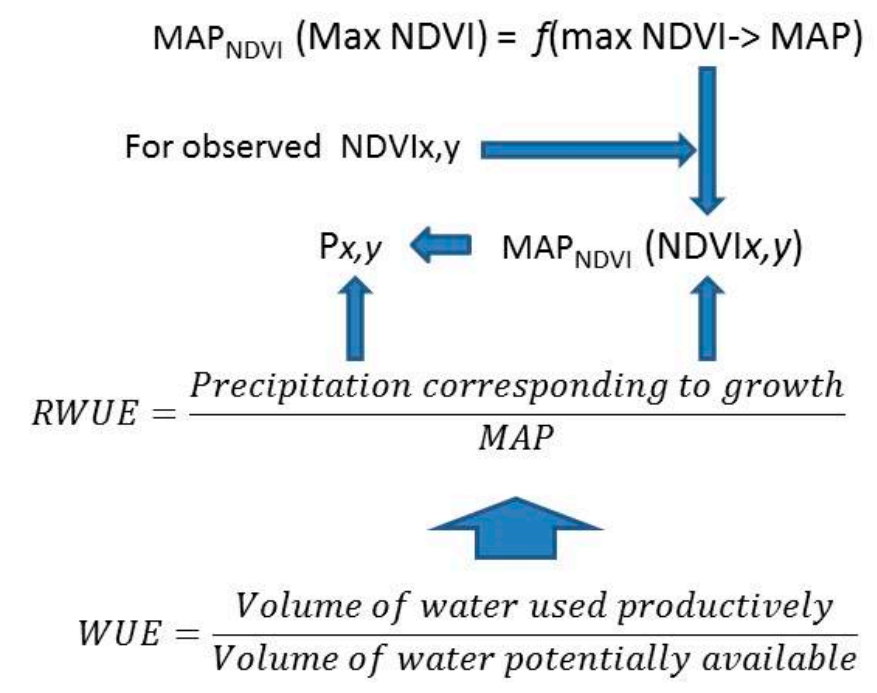

Figure 2. The development of the concept of Relative Water Use Efficiency (RWUE) following the definition of Stanhill [20].

The precipitation level at a location $\mathrm{x}, \mathrm{y}(\mathrm{Px}, \mathrm{y})$ corresponding to an observed NDVIx,y may than be estimated using the MAP ${ }_{\mathrm{NDVI}}$ function:

$$
\operatorname{MAP}_{\mathrm{NDVI}}(\mathrm{NDVI} x, y)=P x, y
$$

Thus, where growth is lower than afforded by its MAP, either due to lower water availability or due to disturbance, its NDVI would correspond to that of an area of lower MAP (defining Px,y). Following these relationships, Relative water-use efficiency (RWUE) at a location x,y is defined as:

$$
R W U E x, y=\frac{P x, y}{M A P x, y}
$$

The range of RWUE values would normally be between 0 and 1 . However, in years of significantly higher than average rainfall, RWUE may reach values higher than 1.

\section{Water-Use-Based Estimates of Shrubland Biomass}

Equation (1) represents the biomass expected when RWUE $=1$. As discussed earlier, a decrease in RWUE stemming from various ecohydrological or human-induced processes is expected to yield a decrease in biomass. We suggest that the biomass response to changes in RWUE can be incorporated within Equation (1) in the following way:

$$
\mathrm{SB}_{\mathrm{RWUE}}=0.008 \mathrm{MAP}^{(0.54+\mathrm{RWUE})}
$$

In a case in which RWUE $=0$, Equation (6) yields a biomass below $0.07 \mathrm{~kg} / \mathrm{m}^{2}$.

Figure 3 presents the results of a simulation of biomass predictions given by this model for different MAP levels as a result of varying RWUE. It suggests that RWUE has an exponential influence on biomass as a result of variations in the former in response to changes in habitat conditions. 


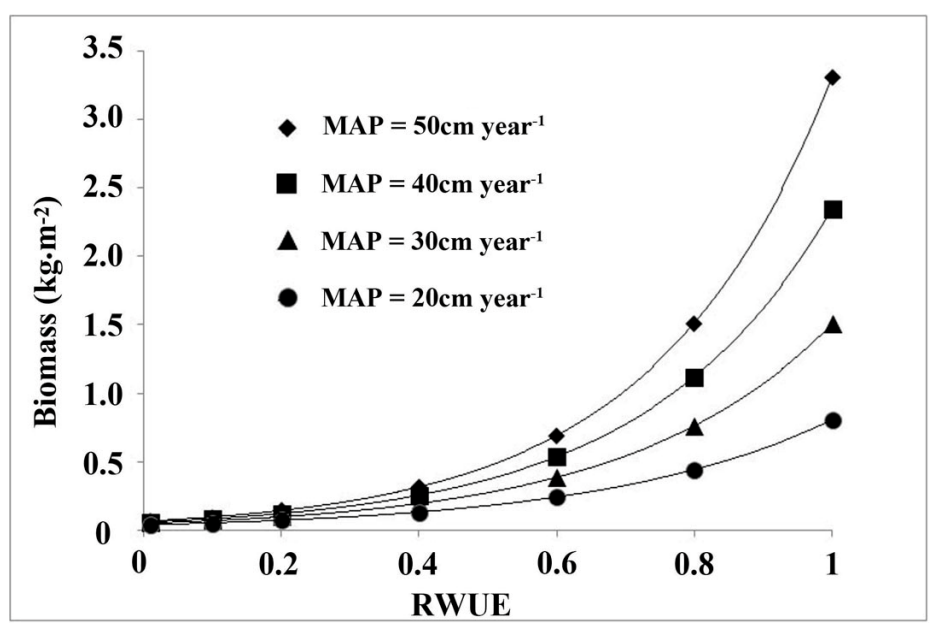

Figure 3. Simulation of the change in biomass predictions by the new Relative Water-Use-Efficiency-Based Model (Equation (6)) for different MAP levels as a result of varying relative water-use efficiency (RWUE).

\section{Study Area}

The study area (Figure 4) extends between the Jerusalem Mountains to the north and the Negev Desert to the south, and between the Judean Lowlands to the west to the margins of the Judean Desert to the east. Mean annual precipitation ranges from $60 \mathrm{~cm} / \mathrm{yr}$ on the Jerusalem Mountain crests to less than $10 \mathrm{~cm} / \mathrm{yr}$ in the east and $20 \mathrm{~cm} / \mathrm{yr}$ in the south. Mean annual temperatures range from $17{ }^{\circ} \mathrm{C}$ in the Jerusalem Mountains to $23{ }^{\circ} \mathrm{C}$ in the eastern margins of the Judean Desert. The shrublands of this transition zone are similar to those found in vast areas across Mediterranean regions having an annual rainfall of between 10 and $50 \mathrm{~cm} / \mathrm{yr}$ (e.g., [29,30]). Ecosystems vary along the climatic transect (e.g., [31]), from the Pinus halepensis and Arbustus woodlands and the Quercus calliprinos woodlands in the sub-humid areas at the top of the Judean and Jerusalem Mountains, with a MAP exceeding $50 \mathrm{~cm} / \mathrm{yr}$; to shrub association dominated by Quercus calliprinos and Pistacia lentiscus in the semi-arid areas of the Judean Lowlands, with a MAP ranging between 35 and $50 \mathrm{~cm} / \mathrm{yr}$; and to the desert fringe batha dominated by Sarcopoterium spinosium and Thymelaea hirusta dwarf shrubs in the transition zone between the Judean Lowlands and the northern Negev, with a rainfall of 35 and $20 \mathrm{~cm} / \mathrm{yr}$, respectively. Figure 5 presents a typical mix of shrubs and dwarf shrubs in the study area.

These Mediterranean ecosystems have long histories of human-nature co-evolution [32], with severe overgrazing, wood cutting, and fire episodes during the Turkish rule and the British Mandate in Palestine. High levels of land degradation existed across the Judean Mountains at the end of the 1940s and still exist in major sections of the areas east of the pre-1967 border between Jordan and Israel (the Green Line). However Sharakas et al. [33] claim that these degradation levels had decreased significantly during last decades. In parallel, recovery, now in advanced stages, has taken place west of this line, thanks to the implementation since the 1950s of conservation and protection policies (e.g., [34,35]). According to Shoshany [36], shrub cover in recovering areas exceeded $70 \%$ during the mid-1990s. Historically, forest fires have caused severe damage to the woodlands and shrublands of the Jerusalem Mountains and Judean Lowlands. According to Tessler et al. [37], most of the fires since 1994 extended over areas of less than $1 \mathrm{~km}^{2}$, except for one large conflagration $\left(12 \mathrm{~km}^{2}\right)$ that occurred in 1995. 
Thus, apart from this latter event, it is unlikely that fires would have been the source of change in large areas during the research period. These reported studies indicate therefore that human disturbance is not expected to present decreasing amount of vegetation cover and biomass across the study area (but still may be found in local areas).

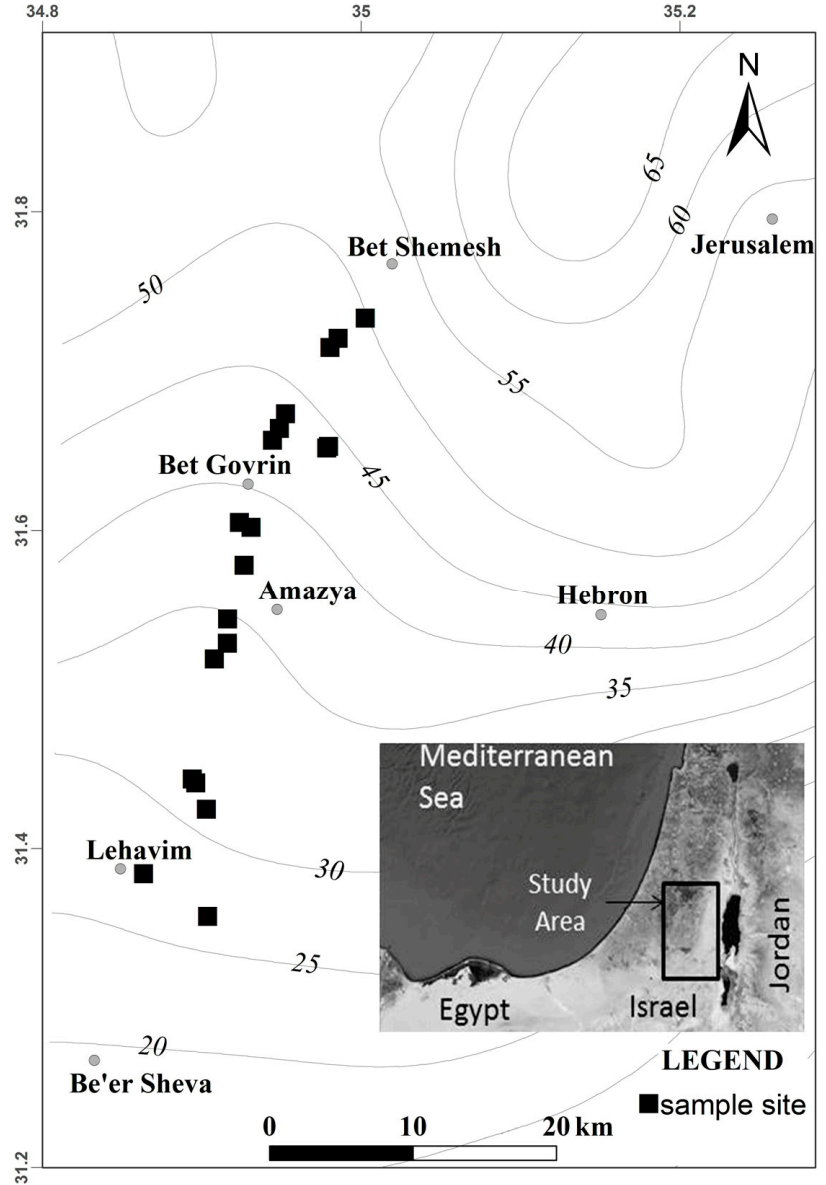

Figure 4. Precipitation levels $(\mathrm{cm} / \mathrm{yr})$ across the study area, with the location of 23 field sampling sites.

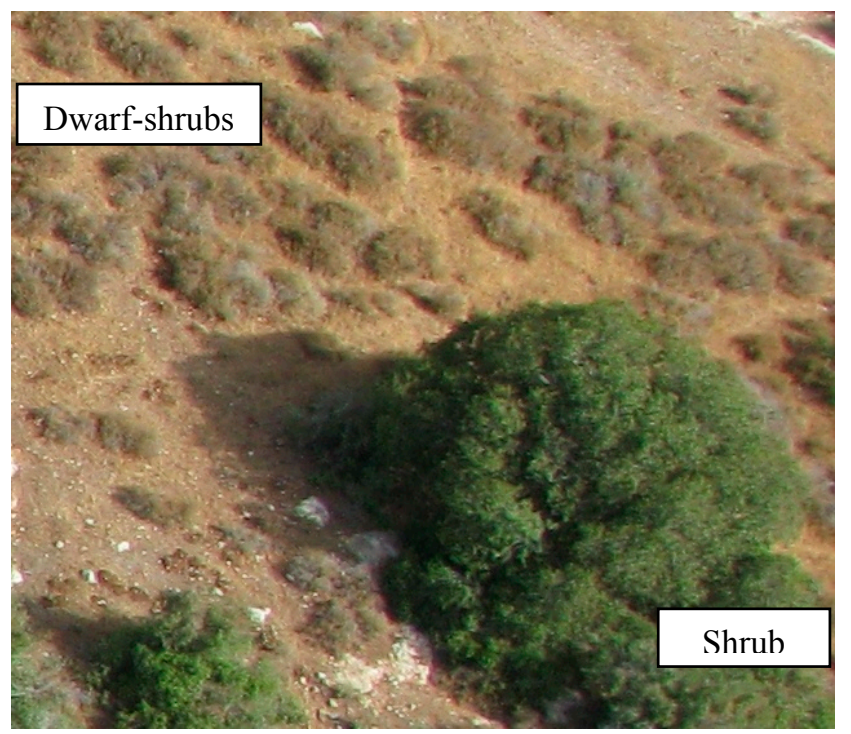

Figure 5. Shrubs and dwarf-shrubs in the Study area. 


\section{Methodology}

The research method consisted of six tasks: (i) gathering information on mean annual precipitation changes between 1994 and 2011; (ii) generalizing the MAP ${ }_{N D V I}$ function (Equation (3)); (iii) mapping RWUE according to Equation (5); (iv) assessing the remotely sensed shrubland-biomass estimates based on allometric measurements; (v) mapping estimated shrubland biomass based on Equation (6); and finally (vi) calculating a biomass-difference map between the beginning and end of the research period.

\subsection{Information Gathering}

To avoid bias from rainfall fluctuations between individual years, we decided to establish the analysis of changes on the average of three years at the beginning and end of the research period. For the whole country, the average rainfall for 1994, 1995 and 1996 was 101\% of the 1931-1990 average (according to data from the Hydrological Service of Israel, 2012), while the average for 2009, 2010 and 2011 reached only $93 \%$ of the 1931-1990 average. Thus, the difference between the 1994-1996 and 2009-2011 average rainfalls might represent a lowering trend at the scale of $8 \%$. However, the fact that between 1994 and 2011 rainfall was lower in 14 years than was the 1931-1990 average suggests an even higher impact of the cumulative deficit in water availability for shrubs.

Cloud-free Landsat TM and ETM images were acquired for three late-summer dates in the mid-1990s (4 October 1994, 7 Octobern 1995 and 23 September 1996) and for three dates from more recent years (27 September 2009, 16 October 2010 and 17 September 2011). The images were geometrically corrected using ground control points, and bands 1-4 were atmospherically corrected based on the Dark Object Subtraction method [38].

Mean annual precipitation data (1980-2010) was acquired from the Israel Meteorological Service (IMS). This data included reports from 131 meteorological stations throughout Israel, of which 21 were selected for the study area. A mean annual precipitation map was produced using the cubic spline interpolation method (ArcGIS 9.3 software, ESRI, Redlands, CA, USA).

\subsection{Formulating the MAP $P_{N D I}$ Function}

The MAPNDVI function was formulated by running a $5 \times 5$ maximum NDVI kernel on the NDVI map generated from the LANDSAT TM imagery for 2010 (a year with $96 \%$ of the MAP) and by sampling NDVI and MAP for regions with a relatively homogenous image regions across the climatic gradient that corresponds to natural vegetation. An exponential equation of the following form was found to characterize these relationships, yielding a curve that fit the data points of maximal NDVI for each MAP level (Figure 6):

$$
\mathrm{MAPNDVI}=80 \mathrm{NDVI}^{0.6}
$$




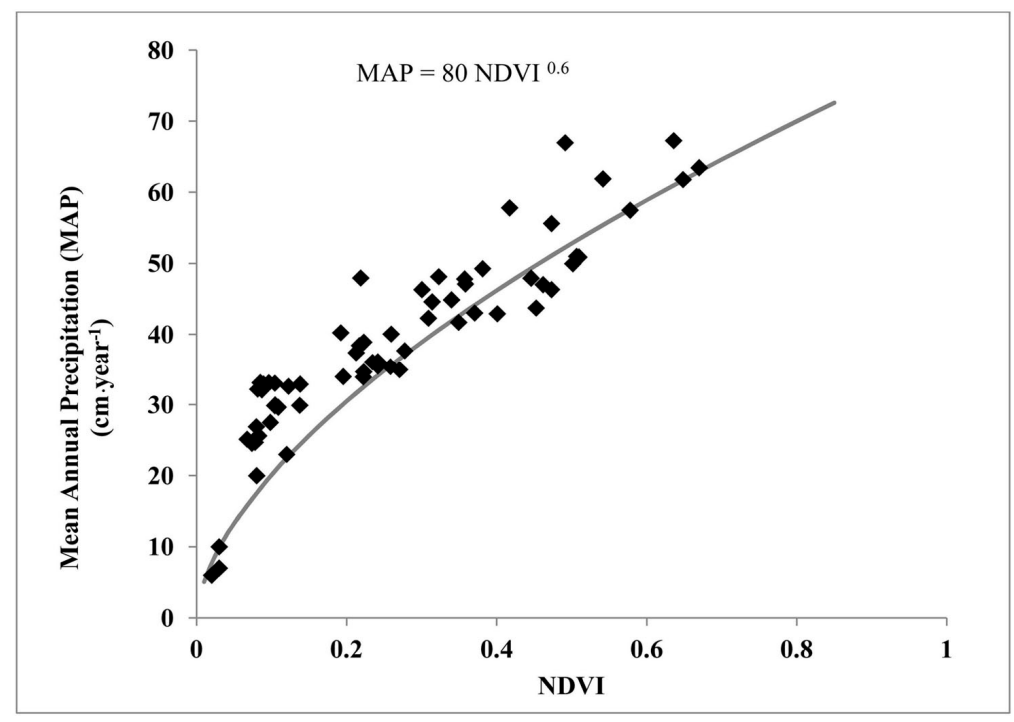

Figure 6. The exponential function generalizing the relationships between MAP (extracted from a map interpolated from the 1980-2010 record of 131 meteorological stations of the Israel Meteorological Service) and maximal NDVI (derived from an October 2010 Landsat TM image).

\subsection{Assessment of the RWUE Shrublands Biomass Model}

Allometric methods were previously implemented to evaluate remote sensing of biomass estimates (e.g., [39]). A shrub's height and radius are the parameters used to estimate the dry biomass of a single shrub. To estimate the aerial biomass of a mosaic of different life-form compositions, we used their relative cover and average height. Sternberg and Shoshany [16] conducted a detailed study of shrub biomass in a semi-arid site ( $45 \mathrm{~cm} / \mathrm{yr}$ rainfall) and in a desert fringe site $(25 \mathrm{~cm} / \mathrm{yr}$ rainfall) that led to the derivation of the following allometric model linking biomass to height:

Shrub Biomass $=0.846$ Shrub Height +0.478

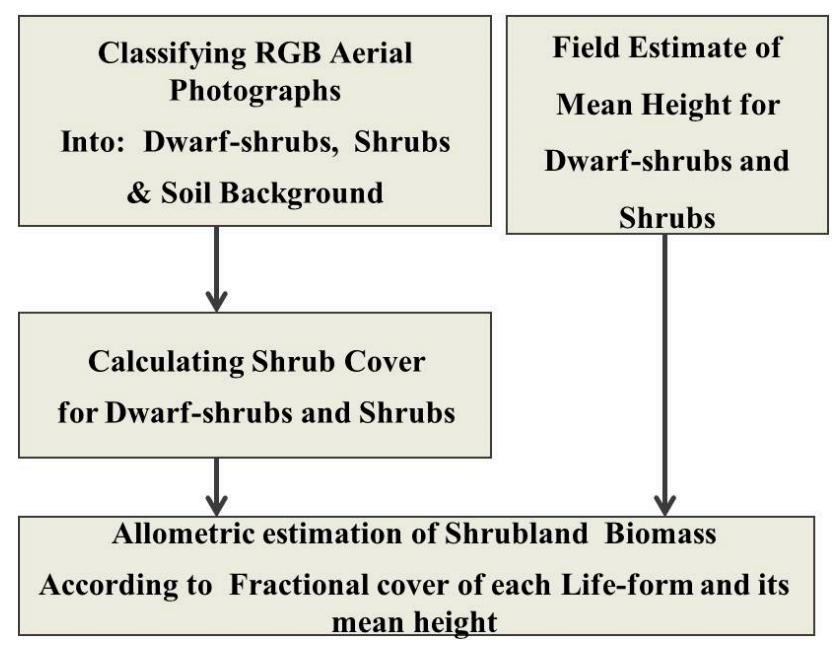

Figure 7. An integrated allometric approach for calculating biomass by combining field estimates of shrub heights with air photography-based estimates of cover fractions for shrub and dwarf shrub life forms. 


\section{NOTHERN SLOPE}
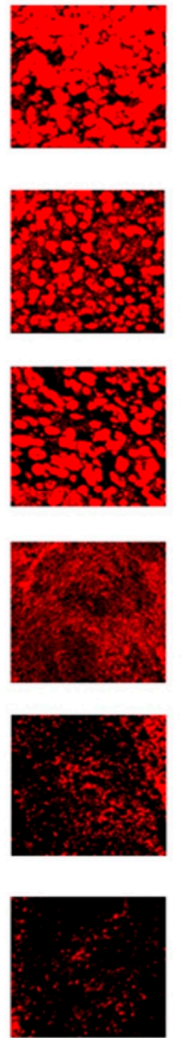
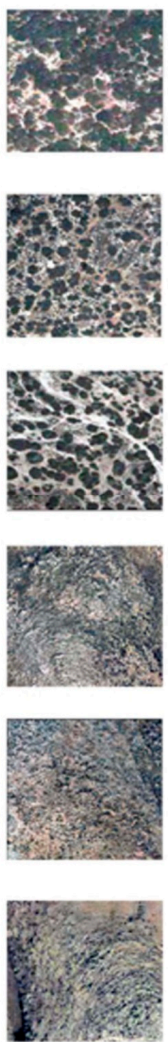

SOUTHERN SLOPE
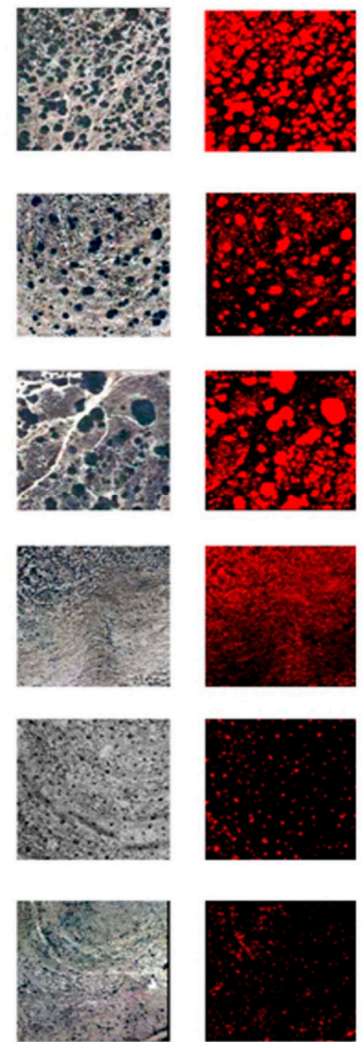

Figure 8. Plot areas extracted from air photographs of six field sites and their segmentation into shrubs versus soil/rock fractions (in red). At each field site there was a plot area in both south and north facing slopes.

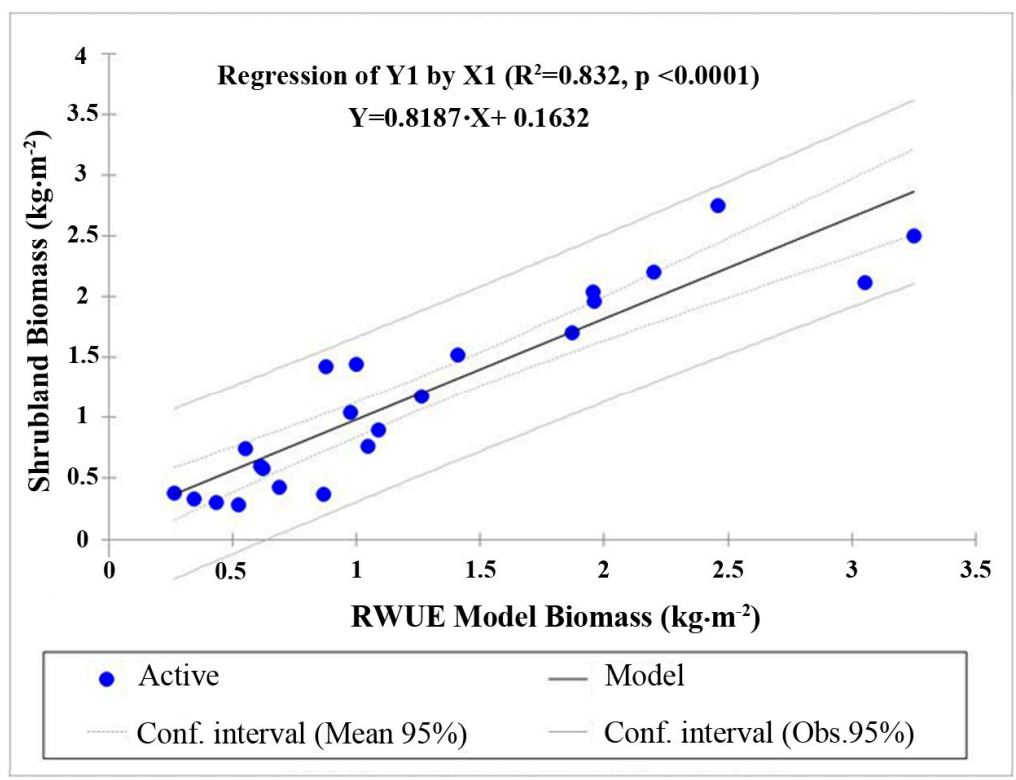

Figure 9. Model (Equation (6)) versus allometric-based estimates of shrubland biomass.

In this study, we developed an integrated approach, combining field estimates of shrub heights with air-photography-based estimates of cover fractions for shrubs and dwarf shrubs (Figure 7). This method was used for 23 sites along the climatic gradient (Figure 4), with MAPs of between $50 \mathrm{~cm} / \mathrm{yr}$ and 
$25 \mathrm{~cm} / \mathrm{yr}$. The air-photographs' information used in this study was derived from the mosaic of digital ortho-photographs ( $0.25 \mathrm{~m}$ ' resolution) built by the Mapping Center of Israel for the summer of 2010. Figure 8 presents plot areas extracted from the air photographs and their segmentation into shrub versus soil/rock fractions. RGB classification was found adequate for separating between the batha dwarf-shrubs and shrubs, and information gathered in the field allowed attachment of height data for each of these life-forms' patches. At each area there were sampled both south and north-facing slopes due to characteristic differences in vegetation patterns and biomass between these slope-aspects across the climatic gradient $[16,36]$.

Model biomass estimates were calculated for each of these 23 sites using Equation (8) and were then compared to results from the allometric calculations. A good correlation was obtained for the new model, which combined MAP and RWUE (Figure 9), and so it was used to estimate shrubland biomass based on NDVI mapped from Landsat TM images.

\subsection{Calculation of Biomass Differences between 1994 and 2011}

NDVI maps were calculated for each of the three years at the beginning and end of the research period. Three NDVI maps (1994, 1995 and 1996) were averaged for the early period, and three (2009, 2010 and 2011) for the late period. Based on the MAP map and calculation of MAPNDVI for each pixel of the averaged NDVI layers (1994-1996 and 2009-2011), corresponding averaged RWUE and biomass maps (Figure 10a,b) were generated using Equations (5), (6) and (8). A difference layer was generated (Figure 11) by subtracting the biomass maps between these two periods.
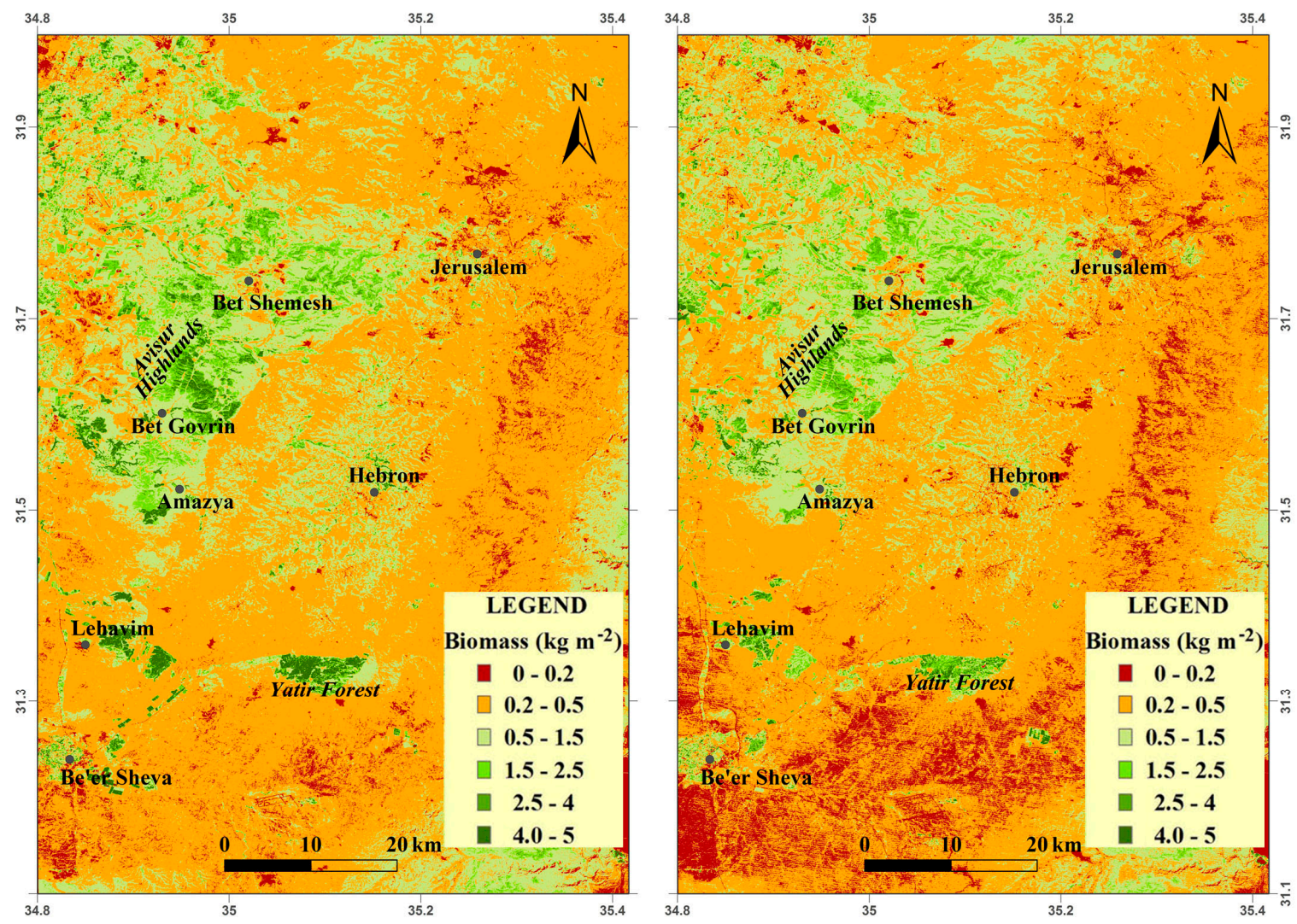

Figure 10. Maps of model-predicted biomass (Equation (5)): Left: average of 1994, 1995 and 1996. Right: average of 2009, 2010 and 2011. 

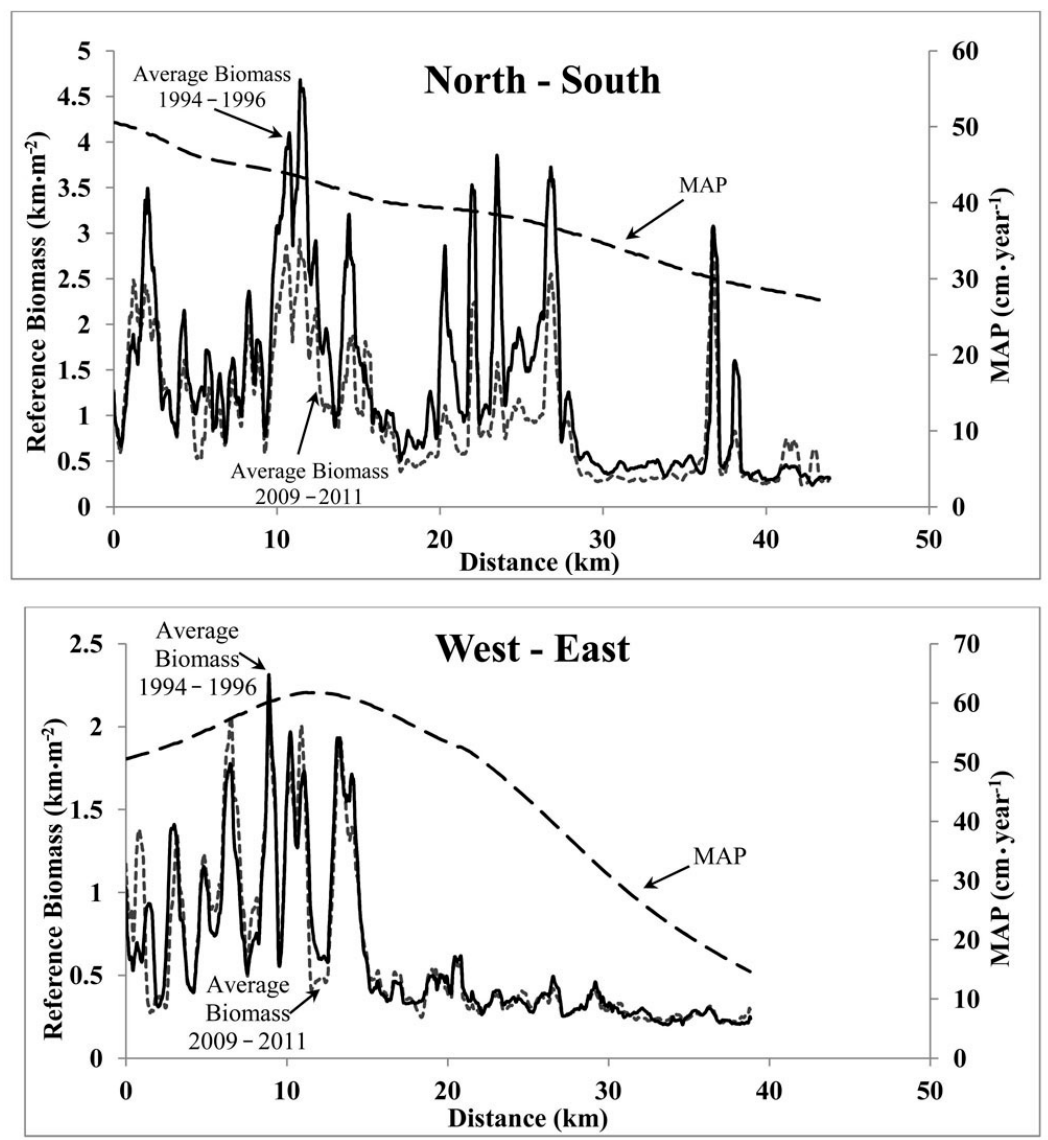

Figure 11. Cross sections of biomass (Figure 10) and MAP: From the Jerusalem Mountains (Bet-Shemesh) eastwards to the Judean Desert and from the Jerusalem Mountains southwards towards the Negev Desert.

\section{Changes in Biomass, 1995-2010}

MAP and biomass were extracted for cross sections of the Jerusalem Mountains (from Bet-Shemesh) eastwards to the Judean Desert and southwards toward the Negev Desert (Figure 11). Biomass along the north-to-south cross section varied from peak levels of $3.5 \mathrm{~kg} / \mathrm{m}^{2}$ in the woodlands of the Jerusalem Mountains, through peak levels of between 3.5 and $4.5 \mathrm{~kg} / \mathrm{m}^{2}$ for the shrublands and plantation areas between the Avisur Highlands (45 cm/yr) and Amazya (35 cm/yr), and ending in a sharp decrease to levels below $0.5 \mathrm{~kg} / \mathrm{m}^{2}$ in the transition zone from Amazya to Lehavim at the Negev Desert margins.

Along the west-to-east cross section, peak biomass values of between 1.5 and $2 \mathrm{~kg} / \mathrm{m}^{2}$ characterize the crest areas of the Judean Mountains, with a drastic decline in biomass (to levels below $0.5 \mathrm{~kg} / \mathrm{m}^{2}$ ) at the desert margins (see discussion regarding vegetation patterns in the desert threshold zone in Shoshany, [40]. An affinity between biomass and MAP variations along the two cross sections may be inferred only for peak biomass levels. The high biomass fluctuations express effects from disturbances, on the one hand, and conservation (including plantations), on the other hand. The two cross sections from the early and late periods generally parallel each other although biomass was higher in a significant number of segments along the north-to-south cross section during 1995, and the greatest decrease in biomass was observed in areas of shrubs and plantations. 


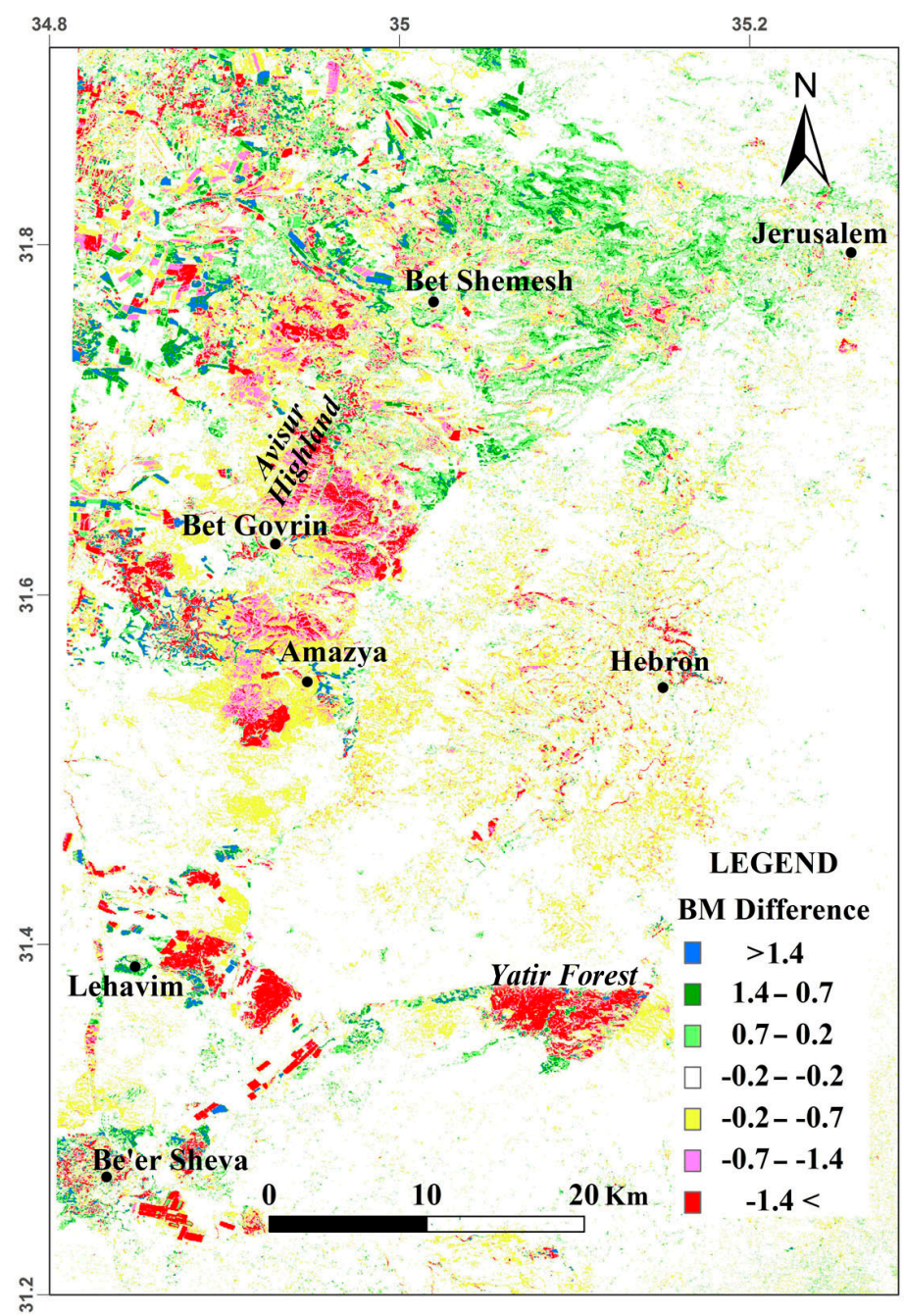

Figure 12. Deviations between the two biomass maps (Figure 8) of the early (1994-1996) and late (2009-2011) periods. Squares: location of detailed analysis units $(2 \times 2 \mathrm{~km}$ in size $)$.

Figure 12 presents the deviations between the biomass estimated in the two periods. The two most profound results concern the dominance of the low-change category $\left(-0.2<d<0.2 \mathrm{~kg} / \mathrm{m}^{2}\right)$ and the high decrease in biomass in planted forests (red areas with $d<-1.4 \mathrm{~kg} / \mathrm{m}^{2}$ difference). A west-to-east line passing through the Avisur Highlands roughly divides the region into areas with a significant presence of increasing biomass in the north and areas with decreasing biomass in the south. Statistics of biomass deviations $(d)$ were then derived for five detailed analysis units representing areas dominated by natural vegetation: the Jerusalem Mountains, the shrubland area between Amazya and the Avisur Highlands, the dwarf shrublands between Amazya and Lehavim, the area south of the Yatir Forest and the area in the Judean Mountains east of the city of Hebron (Figure 13). The proportion of areas with low-change deviation $\left(-0.2<d<0.2 \mathrm{~kg} / \mathrm{m}^{2}\right)$ is substantial in four of the five area units, reaching peak levels of $75 \%$ of the Amazya-Lehavim and Hebron areas; $55 \%$ of the in the Jerusalem unit; and $40 \%$ of the Avisur Highland area. A distinctive increase in biomass is observed in the Jerusalem Mountains unit, where positive deviations $\left(0.2<d<1.4 \mathrm{~kg} / \mathrm{m}^{2}\right)$ were found in $30 \%$ of the area. On the other hand, in the Avisur Highlands-Amazya unit, there is a significant decrease in biomass $\left(-1.4<d<-0.2 \mathrm{~kg} / \mathrm{m}^{2}\right)$ in about $50 \%$ of the area. In the Amazya-Lehavim unit, there is a moderate decrease $\left(-0.7<d<-0.4 \mathrm{~kg} / \mathrm{m}^{2}\right)$ in $18 \%$ of the area. The area south of the Yatir Forest presents a predominant decrease in biomass in the low 
negative-deviation category $\left(-0.4<d<-0.2 \mathrm{~kg} / \mathrm{m}^{2}\right)$ in more than $90 \%$ of the area. This last result is explained by the removal of the upper soil layer, including dwarf shrubs, during preparation of the area for planting trees within the framework of an afforestation initiative.

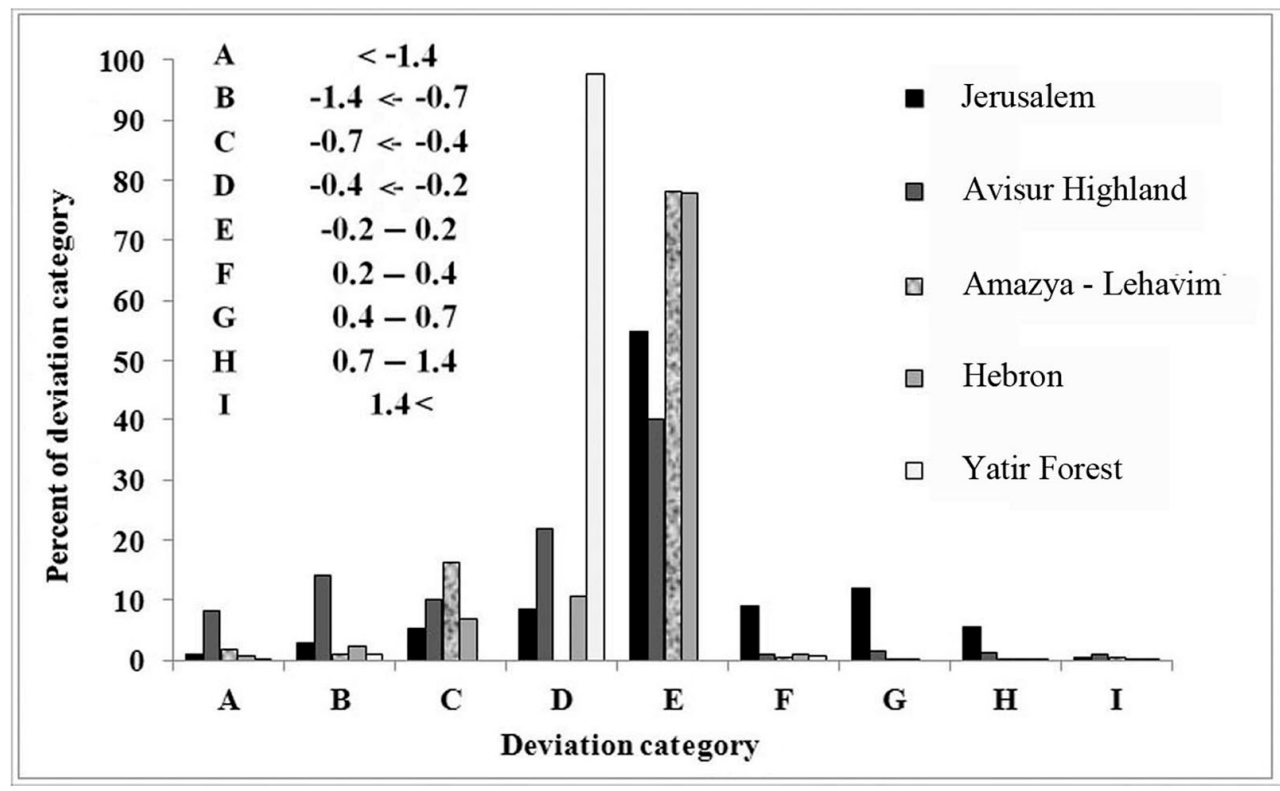

Figure 13. Percentage area for different deviation categories as derived from detailed analysis units in the Jerusalem Mountains, the Avisur Highlands, Amazya-Lehavim, Hebron and Yatir Regions.

\section{Discussion}

Recent studies suggest that extreme climatic conditions may have had significant effects on the Mediterranean and semi-arid ecosystems. Droughts are among the most environmentally damaging extreme-climate conditions worldwide [41]. In a recent review, Allen et al. [42] pointed out that more than 10 million ha of forests, woodlands and savannas have suffered from diebacks of trees and plants from droughts since 1997. Another study, conducted in a Mediterranean-type eucalyptus forest in Western Australia, reports a canopy collapse resulting from extreme drought and heat conditions [43]. Several studies reported on the increasing frequency of drought conditions in the lands surrounding the Mediterranean (e.g., [44,45]). In 2012, Hoerling et al. [46] published a map showing that the south-east Mediterranean constituted a prominent hot spot of dry winters between 1971 and 2010. A report issued by the United Nations Office for Disaster Risk Reduction noted the decline of ecosystems in this region owing to a water deficit of about 651 million $\mathrm{m}^{3}$ during the years 1995-2005 caused by an increase in drought frequency [47].

Implementation of remote sensing for the identification of structural changes in shrublands in response to droughts was presented by Paz-Kagan [5]. A study of damages to Mediterranean forests in Israel has been reported by, among others, Volcani et al. [48] and Dorman et al. [49], the latter using a normalized-difference water index to represent water content in trees. However, to the best of our knowledge, there is no data regarding changes in the biomass of semi-arid shrublands and dwarf shrublands over the past 20 years that can be linked to the general phenomenon of ecological drought damage. 
Biomass mapping based on relative water-use efficiency is instrumental for this purpose, as it strongly links biomass to water availability. Our results present new evidence regarding the extent of change in natural vegetation in the southeastern Mediterranean. Mixed trends were observed in the Mediterranean woodlands and shrublands of the Jerusalem Mountains, with a significant presence of areas with a biomass increase. There is distinctive evidence of decreasing biomass across a wide range of shrublands, dwarf-shrublands and plantations from the Avisur Highlands $(45 \mathrm{~cm} / \mathrm{yr})$ southward. Since human disturbance had not increased across the study area (e.g., [33-35]), these results support the findings of Ziv et al. [50] and Kafle and Bruins [51] and suggesting increasing aridity in desert fringe ecosystems. However, it is important to mention that the finding reported for the areas south of Yatir Forest is the result of the afforestation works initiated by the Forest Commission of the JNF (Jewish National Fund) during the late 1990s in order to combat desertification in this region. The early stages of this afforestation involves removal of the upper soil and dwarf shrub layer, which explains the reduction of biomass. This initiative had generated significant conflict between the Forest Commission people [52] and the Society for the Preservation of Nature [53] whether such intervention into the natural processes was justified.

\section{Summary and Conclusions}

A new technique for biomass mapping, based on relative water-use efficiency, was presented. A comparison of the model predictions with data from allometric calculations validated the model and enabled its application along the climatic gradient between the Jerusalem Mountains and the Judean Desert to the east and the Negev Desert to the south. This gradient is characterized by biomass variations of between $4.5 \mathrm{~kg} / \mathrm{m}^{2}$ and $0.2 \mathrm{~kg} / \mathrm{m}^{2}$ (X 22), which creates an extremely steep geographical decrease over a distance of $25 \mathrm{~km}$; by comparison, MAP decreases over the same distance by only from $60 \mathrm{~cm} / \mathrm{yr}$ to $20 \mathrm{~cm} / \mathrm{yr}$ (X 3). Furthermore, the strong fluctuations in productivity (Figure 9) are indicative of the level of historical influences that are due to human disturbance and variations in recovery stages and rates. Subtracting the 1995 average biomass from the 2010 average (Figure 10) provided an insight into the changes that have occurred in the semi-arid and Negev Desert fringe ecosystems. About half of the entire study area is characterized by the low-change category, and between $20 \%$ and $30 \%$ represent areas of high deviation linked to human activities, such as cultivation, overgrazing, logging and fire in planted forests. A predominant trend of biomass increase is evident north of the Avisur Highlands line, while south of this line there is significant indication of a loss of productivity. These results are consistent with the fact that annual rainfall in Israel was lower than the 1931-1990 average for 12 of the 15 years of the research period. They support recent findings from both climate-change modeling [3] and rainfall-change trends $[50,51]$ that suggest a decrease in water availability and, consequently, the drying of vegetation across wide desert fringe ecosystems. The results presented here and their ecological implications necessitate further, focused research on change in shrubland conditions across semi-arid regions using both field and remote-sensing techniques.

\section{Acknowledgment}

The Israel Science Foundation supported this study through Grant No. 1286/12. The Tempus Program for Strengthening education in space-based remote sensing for monitoring of eco systems (Project Nr.: 543720-TEMPUS-1-2013-1-DE-TEMPUS-JPCR) supported publication of this article. 


\section{Author Contributions}

This study is part of the $\mathrm{PhD}$ research of Lev Karnibad conducted under the supervision and guidance of Maxim Shoshany.

\section{Conflicts of Interest}

The authors declare no conflict of interest.

\section{References}

1. Giorgi, F.; Lionello, P. Climate change projections for the Mediterranean region. Glob. Planet. Change 2008, 63, 90-104.

2. Lelieveld, J.; Hadjinicolaou, P.; Kostopoulou, E.; Chenoweth, J.; El Maayar, M.; Giannakopoulos, C.; Hannides, C.; Lange, M.A.; Tanarhte, M.; Tyrlis, E.; Xoplaki, E. Climate change and impacts in the Eastern Mediterranean and the Middle East. Clim. Change 2012, 114, 667-687.

3. Mariotti, A.; Zeng, N.; Yoon, J.-H.; Artale, V.; Navarra, A.; Alpert, P.; Li, L.Z.X. Mediterranean water cycle changes: transition to drier 21 st century conditions in observations and CMIP3 simulations. Environ. Res. Lett. 2008, 3, 044001.

4. Hydrological Service of Israel Summation of the 2011/2012 Rainfall Year and Its Hydrological Principle Characteristics; Israel Water Authority: Jerusalem, Israel, 2012.

5. Paz-Kagan, T.; Panov, N.; Shachak, M.; Zaady, E.; Karnieli, A. Structural changes of desertified and managed shrubland landscapes in response to drought: Spectral, spatial and temporal analyses. Remote Sens. 2014, 6, 8134-8164.

6. Verón, S.R.; Paruelo, J.M. Desertification alters the response of vegetation to changes in precipitation. J. Appl. Ecol. 2010, 47, 1233-1241.

7. Safriel U. Status of desertification in the Mediterranean region. In Water Security, Land Degradation and Desertification in the Mediterranean Region; Rubio, J.L., Rubio, J.L., Daussa, R., Blum, W., Pedrazzini, F., Eds.; Springer: Berlin, Germany, 2009; pp. 33-43.

8. Prieto, P.; Peñuelas, J.; Llusià, J.; Asensio, D.; Estiarte, M. Effects of experimental warming and drought on biomass accumulation in a Mediterranean shrubland. Plant Ecol. 2009, 205, 179-191.

9. Sonnenschein, R.; Kuemmerle, T.; Udelhoven, T.; Stellmes, M.; Hostert, P. Differences in Landsat-based trend analyses in drylands due to the choice of vegetation estimate. Remote Sens. Environ. 2011, 115, 1408-1420.

10. Eisfelder, C.; Kuenzer, C.; Dech, S. A review on derivation of biomass information in semi-arid regions based on remote sensing data. Proc. SPIE 2010, doi:10.1117/12.868505.

11. Lu, D. The potential and challenge of remote sensing-based biomass estimation. Int. J. Remote Sens. 2006, 27, 1297-1328.

12. Shoshany, M.; Karnibad, L. Mapping shrubland biomass along Mediterranean climatic gradients: The synergy of rainfall-based and NDVI-based models. Int. J. Remote Sens. 2011, 32, 9497-9508.

13. Emmerich, W.E. Ecosystem Water use efficiency in a semiarid shrubland and grassland community. Rangel. Ecol. Manag. 2007, 60, 464-470. 
14. Shoshany, M. The rational model of shrubland biomass, pattern and precipitation relationships along semi-arid climatic gradients. J. Arid Environ. 2012, 78, 179-182.

15. Evenari, M.; Bamberg, S.; Schulze, E.D.; Kappen, L.; Lange, L.O.; Buschbom, U. The biomass production of some higher plants in near-Eastern and American deserts. In Photosynthesis and Productivity in Different Environments; Cooper, J.P., Ed.; Cambridge University Press: Cambridge, UK, 1975; pp. 121-128.

16. Sternberg, M.; Shoshany, M. Influence of slope aspect on Mediterranean woody formations: Comparison of a semiarid and an arid site in Israel. Ecol. Res. 2001, 16, 335-345.

17. Cerrillo, R.M.N.; Oyonarte, P.B. Estimation of above-ground biomass in shrubland ecosystems of southern Spain. Investig. Agrar. Sist. Recur. For. 2006, 15, 197-207.

18. Alrababah, M.A.; Alhamad, M.N.; Bataineh, M.M. Arboreal diversity and aboveground biomass in a semi-arid Mediterranean forest ecosystem: Case of Kufur-Khal natural reserve. Jordan J. Agric. Sci. 2007, 3, 363-375.

19. Sağlam, B.; Küçük, Ö.; Bilgili, E.; Durmaz, B.D.; Baysal, I. Estimating fuel biomass of some shrub species (maquis) in Turkey. Turkish J. Agric. For. 2008, 32, 349-356.

20. Stanhill, G. Water use efficiency. Adv. Agron. 1986, 39, 53-85.

21. Kustas, W.P.; Norman, J.M. Use of remote sensing for évapo-transpiration monitoring over land surfaces. Hydrol. Sci. J. 1996, 41, 495-516.

22. Lu, X.; Zhuang, Q. Evaluating evapotranspiration and water-use efficiency of terrestrial ecosystems in the conterminous United States using MODIS and AmeriFlux data. Remote Sens. Environ. 2010, 114, 1924-1939.

23. Hein, L.; De Ridder, N. Deserti cation in the Sahel: A reinterpretation. Glob. Chang. Biol. 2006, $12,751-758$.

24. Prince, S.D.; Wessels, K.J.; Tucker, C.J.; Nicholson, S.E. Desertification in the Sahel: A reinterpretation of a reinterpretation. Glob. Chang. Biol. 2007, 13, 1308-1313.

25. Shoshany, M.; Svoray, T. Multidate adaptive unmixing and its application to analysis of ecosystem transitions along a climatic gradient. Remote Sens. Environ. 2002, 82, 5-20.

26. Herrmann, S.M.; Anyamba, A.; Tucker, C.J. Recent trends in vegetation dynamics in the African Sahel and their relationship to climate. Glob. Environ. Chang. 2005, 15, 394-404.

27. Diouf, A.; Lambin, E.F. Monitoring land-cover changes in semi-arid regions: remote sensing data and field observations in the Ferlo, Senegal. J. Arid Environ. 2001, 48, 129-148.

28. Nicholson, S.E.; Davenport, M.L.; Malo, A.R. A comparison of the vegetation response to rainfall in the Sahel and East Africa, using normalized difference vegetation index from NOAA AVHRR. Clim. Change 1990, 17, 209-241.

29. Peinado, M.; Alcaraz, F.; Aguirre, J.L.; Delgadillo, J.; Aguado, I. Shrubland formations and assosiation in mediterranean-desert transitional zones of northwestern Baja California. Vegetatio 1995, 117, 165-179.

30. Danin, A.; Orshan, G.; Zohary, M. The vegetation of nothern negev and judean desert. Isr. J. Bot. 1975, 24, 118-172.

31. Danin, A. Flora and vegetation of Israel and adjacent areas. Bocconea 1992, 3, 18-42. 
32. Naveh, Z.; Carmel, Y. the Evolution of the cultural Mediterranean landscape in Israel as affected by fire, grazing, and humanactivities. In Evolutionary Theory and Processes: Modern Horizons, Papers in Honour of Eviatar Nevo; Wasser, S.P., Ed.; Kluwer Academic Publishers: Dordrecht, The Nethelands, 2003; pp. 337-409.

33. Sharakas, O.; Hammad, A.A.; Nubani, A.; Abdullah, A. Land Degradation Risk Assessment in the Palestinian Central Mountains Utilizing Remote Sensing and GIS Technique (Research Report); Geography Department, Birzeit University: Birzeit, Palestine, 2006; p. 97.

34. Grunzweig, J.M. Briefing Notes on the CIRCE Rural Case Studies: The Judean Foothills; CIRCLE Climate Change and Impact Research: The Mediterranean Environment, 2008. Available online: http://www.cru.uea.ac.uk/projects/circe/JudeanFoothills.html (accessed on 23 December 2014).

35. Stern, E.; Reiter, R.; Frumkin, R. Biosphere Reserve in the Judean Foothills-Method, Outline and Structure; Final Report; Tel-Aviv, Israel, 2004 (In Hebrew).

36. Shoshany, M. Landscape fragmentation and soil cover changes on south- and north-facing slopes during ecosystems recovery: An analysis from multi-date air photographs. Geomorphology 2002, $45,3-20$.

37. Tessler, N.; Malkinson, D.; Vitenberg, L.; Grinbaum, N. Forest and woodland fires in the Carmel and Jerusalem Mountains-Documentation and analysis of temporal patterns. Horizons 2010, 76, 157-165 (In Hebrew).

38. Song, C.; Woodcock, C.E.; Seto, K.C.; Lenney, M.P.; Macomber, S.A. Classification and change detection using Landsat TM data: When and how to correct atmospheric effects? Remote Sens. Environ. 2001, 75, 230-244.

39. De Jong, S.M.; Pebesma, E.J.; Lacaze, B. Above ground biomass assessment of Mediterranean forests using airborne imaging spectrometry: The DAIS Peyne experiment. Int. J. Remote Sens. 2003, 24, 1505-1520.

40. Shoshany, M. Desert threshold identification by maximizing potential instability in soil and shrubs' patterns: A remote sensing study. Land. Degrad. Dev. 2012, 23, 331-338.

41. Kogan, F.N. Global drought watch from space. Bull. Am. Meteorol. Soc. 1997, 78, 621-636.

42. Allen, C.D.; Macalady, A.K.; Chenchouni, H.; Bachelet, D.; McDowell, N.; Vennetier, M.; Kitzberger, T.; Rigling, A.; Breshears, D.D.; Hogg, E.H.(T.); Gonzalez, P.; Fensham, R.; Zhang, Z.; Castro, J.; Demidova, N.; Lim, J.H.; Allard, G.; Running, S.W.; Semerci, A.; Cobb, N. A global overview of drought and heat-induced tree mortality reveals emerging climate change risks for forests. For. Ecol. Manage. 2010, 259, 660-684.

43. Matusick, G. Drought and heat triggers sudden and severe dieback in a dominant Mediterranean type woodland species. Open J. For. 2012, 02, 183-186.

44. Gao, Y.; Fu, J.S.; Drake, J.B.; Liu, Y.; Lamarque, J.-F. Projected changes of extreme weather events in the eastern United States based on a high resolution climate modeling system. Environ. Res. Lett. 2012, 7, 1-12.

45. Ruffault, J.; Martin-StPaul, N.K.; Rambal, S.; Mouillot, F. Differential regional responses in drought length, intensity and timing to recent climate changes in a Mediterranean forested ecosystem. Clim. Change 2013, 117, 103-117.

46. Hoerling, M.; Eischeid, J.; Perlwitz, J.; Quan, X.; Zhang, T.; Pegion, P. On the increased frequency of mediterranean drought. J. Clim. 2012, 25, 2146-2161. 
47. Erian, W.; Katlan, B.; Ouldbedy, B.; Awad, H.; Zaqhtity, E.; Ibrahim, S. Agricultural Drought in Africa Mediterranean and Middle East; Background Paper Prepared for the Global Assessment Report on Disaster Risk Reduction; United Nations Office for Disaster Risk Reduction: Geneva, Switzerland, 2013; p. 402.

48. Volcani, A.; Karnieli, A.; Svoray, T. The use of remote sensing and GIS for spatio-temporal analysis of the physiological state of a semi-arid forest with respect to drought years. For. Ecol. Manage. 2005, 215, 239-250.

49. Dorman, M.; Svoray, T.; Pre, A. Drying trees in the Jerusalem pine forests of Israel—From a high altitude point of view. Ecol . Environ. 2012, 3, 230-237 (In Hebrew).

50. Ziv, B.; Saaroni, H.; Pargament, R.; Harpaz, T.; Alpert, P. Trends in rainfall regime over Israel, 1975-2010, and their relationship to large-scale variability. Reg. Environ. Chang. 2013, 14, 1751-1764.

51. Kafle, H.K.; Bruins, H.J. Climatic trends in Israel 1970-2002: Warmer and increasing aridity inland. Clim. Change 2009, 96, 63-77.

52. Sachs, M.; Itshack, M. Savanization: An ecological viable management approach to desertified regions. In Arid Lands Management: Toward Ecological Sustainability; Hoekstra, T.W., Shachak, M., Eds.; University of Illinois Press: Champaign, IL, USA, 1999; pp. 248-253.

53. Rotem, G.; Bouskila, A.; Rothschild, A. Ecological Effects of Afforestation in the Northern Negev; Report of the Society for the Protection of Nature in Israel; Environmental Protection Division, Society for the Protection of Nature in Israel: Tel-Aviv, Israel, 2014. Available online: http://www.teva.org.il/_Uploads/dbsAttachedFiles/forestration_northern_NegevSPNI_Eng_final May2014.pdf (accessed on 14 February 2015).

(C) 2015 by the authors; licensee MDPI, Basel, Switzerland. This article is an open access article distributed under the terms and conditions of the Creative Commons Attribution license (http://creativecommons.org/licenses/by/4.0/). 